\title{
Breast Angiosarcoma
}

National Cancer Institute

\section{Source}

National Cancer Institute. Breast Angiosarcoma. NCI Thesaurus. Code C5184.

A malignant vascular neoplasm arising from the breast. 